\title{
Genetic Diversity and Population Structure Analysis of Chinese Wild Grape Using Simple Sequence Repeat Markers
}

\author{
Beibei Li \\ College of Enology, Northwest Agriculture \& Forestry University, Yangling, 712100, China; and \\ Zhengzhou Fruit Research Institute of the Chinese Academy of Agricultural Sciences, Zhengzhou, \\ 450009, China \\ Xiucai Fan, Ying Zhang, Chonghuai Liu, and Jianfu Jiang \\ Zhengzhou Fruit Research Institute of the Chinese Academy of Agricultural Sciences, Zhengzhou, \\ 450009, China
}

\begin{abstract}
AdDitIONAL INDEX wORDs. genetic structure and differentiation, genetic variability, molecular markers, SSR, Vitis
Abstract. Chinese wild Vitis is a useful gene source for resistance to biotic and abiotic stresses, although there is little research on its genetic diversity and structure. In this study, nine simple sequence repeat (SSR) markers were used to assess the genetic diversity and genetic structure among 100 Vitis materials. These materials included 77 indigenous accessions representing 23 of 38 wild Vitis species/cultivars in China, 18 V. vinifera cultivars, and the five North American species $V$. aestivalis, $V$. girdiana, $V$. monticola, $V$. acerifolia, and $V$. riparia. The SSR loci used in this study for establishing an international database (Vitis International Variety Catalogue) revealed a total of 186 alleles in 100 Vitis accessions. The mean values for the gene diversity (GD) and polymorphism information content (PIC) per locus were 0.91 and 0.90 , respectively, which indicates that the discriminatory power of the markers is high. Based on the genetic distance data, the $\mathbf{1 0 0}$ Vitis accessions were divided into five primary clusters by cluster analysis, and five populations by structure analysis; these results indicate these Chinese wild grapes were more genetically close to European grapes than to North American species. In addition, the clustering patterns of most accessions correlated with the geographic distribution. An analysis of molecular variance (AMOVA) revealed that 3.28\%, 3.27\%, and $\mathbf{9 3 . 4 6 \%}$ of the variance occurred between populations, between individuals within populations, and between individuals within the entire population, respectively. In addition, we identified three previously undescribed accessions (Wuzhi-1, MZL-5, and MZL-6) by cluster analysis. Our results reveal a high level of genetic diversity and variability in Vitis from China, which will be helpful in the use of genetic resources in future breeding programs. In addition, our study demonstrates that SSR markers are highly suitable for further genetic diversity analyses of Chinese wild grapes.
\end{abstract}

\begin{abstract}
Grapes (Vitis sp.) are one of the most economically valuable horticultural crops in the world. They are widely used to produce wine, table grapes, raisins, juice, and health care products (Ren and Wen, 2007; Wan et al., 2013; Zhou et al., 2017). The genus, which includes more than 70 Vitis species, consists of two subgenera-Vitis and Muscadinia-in which more than 38 Vitis species originated from China (Liu et al., 2012; Wan et al., 2008). Currently, most cultivated grapes in China originated from Europe, and grape commercial breeding populations in China share a narrow genetic base as a result of their common origins from a number of popular cultivars, such as Muscat Hamburg and Kyoho. However, China, as one of the major gene centers of Vitis species, has abundant wild grape species that occur naturally in all the provinces except Xinjiang, and the number of wild grape species per province ranges from 1 to 29 (Jiang et al., 2015). Chinese wild grapes have strong abiotic stress tolerance and could be widely used for modern grape breeding (Liu et al., 2014; Wan et al., 2013). There is still
\end{abstract}

Received for publication 5 Nov. 2020. Accepted for publication 22 Jan. 2021. Published online 8 March 2021.

C.L. and J.J. are corresponding authors. E-mail: liuchonghuai@caas.cn or jiangjianfu@caas.cn.

This is an open access article distributed under the CC BY-NC-ND license (https://creativecommons.org/licenses/by-nc-nd/4.0/). a great interest among grape breeders in broadening the genetic base of cultivated grapes and also in tapping into the gene pool of the wild relatives to enhance stress resistance.

Traditionally, the methods used for assessing the genetic diversity and relationships among wild grape species have relied mostly on morphology, palynology, and isoenzymes (Chao and Niu, 1981; He and Chao, 1982; Wan et al., 2008). However, these methods are easily affected by environmental conditions and developmental stages (Luo et al., 2001). Fortunately, DNA molecular marker techniques are able to overcome these limitations and act as powerful tools for evaluating genetic diversity and relationships (Guan et al., 2019; Queiroz et al., 2015; Riaz et al., 2018). Therefore, a variety of molecular markers, such as random amplified polymorphic DNA (Luo et al., 2001)], intersimple sequence repeat (Jing and Wang, 2013; Zhang et al., 2011)], sequence-related amplified polymorphism (SRAP) (Liu et al., 2013), and SSR (Jing et al., 2013; Liu et al., 2012)], have been used recently to examine the genetic diversity and relationships among wild Chinese grape species. Klein et al. (2018) also used high-throughput sequencing to clarify evolutionary relationships among North American Vitis species. Because SSR markers show high levels of polymorphisms, reproducibility, and codominant inheritance (Aradhya et al., 2013; Li et al., 2017), they have been widely used to study 
the genetic diversity of grapes (Cao et al., 2020; Guo et al., 2010), sugarcane [Saccharum officinarum (Ali et al., 2019)], wheat [Triticum aestivum (Abbasov et al., 2018)], cabbage [Brassica oleracea (El-Esawi et al., 2016)], and hazelnuts [Corylus heterophylla (Zhao et al., 2020)].

Early research focused on the classification of Chinese wild grapes, but the taxonomic status of many of the indigenous Chinese species and cultivars remains obscure, such as $V$. amurensis var. yanshanensis (Zhang et al., 2018). Later, as a result of the importance of wild grapes in breeding, a number of reports focused on the analysis of genetic diversity among wild grapes native to China and cultivated grapes originating from North America and Europe (Jing and Wang, 2013; Jing et al., 2013; Péros et al., 2011). However, there is still a need to investigate further the genetic diversity of wild grape resources to enable breeders to broaden the genetic base of cultivated grapevines through the incorporation of wild relatives (Fan et al., 2015; Jing et al., 2013; Liu et al., 2012; Zhang et al., 2018).

Recently, Liu et al. (2012) used SSR and SRAP to analyze the genetic diversity of 15 Chinese wild grape species (Liu et al., 2012). To understand more fully the genetic background of Chinese wild grapes, we extend that work in this study to include 23 species/cultivars, in which most wild species are included. This study aimed to characterize the genetic diversity and population structure of 100 accessions belonging to Chinese wild Vitis species/cultivars, $V$. vinifera, $V$. aestivalis, $V$. girdiana, $V$. monticola, $V$. acerifolia, and $V$. riparia. The results may provide invaluable information for the better use of Chinese wild grape germplasms in breeding. Moreover, to connect our findings with the Vitis International Variety Catalogue database (Maul and Töpfer, 2015), we assessed the genetic diversity and relationships of 100 Vitis materials standardized by using the nine SSR markers used in the database to obtain useful information on these materials. The genotypes obtained in this study can be connected to the Vitis International Variety Catalogue database after standardization, which will facilitate the sharing of information among different laboratories.

\section{Materials and Methods}

Plant materials. Plant materials were collected from the China Grape Germplasm Repository in Zhengzhou Henan Province. A total of 100 Vitis accessions were used in this study. They consisted of 77 accessions representing 23 Chinese wild Vitis species/cultivars, $18 \mathrm{~V}$. vinifera cultivars, and the North American $V$. aestivalis, $V$. girdiana, $V$. monticola, $V$. acerifolia, and $V$. riparia. Moreover, four cultivars of the $18 \mathrm{~V}$. vinifera cultivars were used for SSR standardization for comparison within international databases (Table 1). The young leaves of each accession were harvested and stored at $-80{ }^{\circ} \mathrm{C}$ for later DNA extraction.

Genomic DNA extraction and Genotyping. Genomic DNA was extracted from the young leaves using a Plant Genomic DNA Kit (Aidlab, Beijing, China) according to the manufacturer's instructions. The DNA quality was checked by $1 \%(\mathrm{w} / \mathrm{v})$ agarose gel electrophoresis. The genomic DNA was diluted to 30 to $50 \mathrm{ng} \cdot \mu \mathrm{L}^{-1}$ and was stored at $-20{ }^{\circ} \mathrm{C}$.

Nine SSR loci distributed over six chromosomes in the grape were used, and they have shown a high discrimination capacity: VVMD5 and VVMD7 (Bowers et al., 1996); VVS2 (Thomas and Scott 1993); VVMD 32, VVMD25, VVMD27, and
VVMD28 (Bowers et al., 1999); and VrZAG62 and VrZAG79 (Sefc et al., 1999). All the forward primers were labeled with FAM (Carboxyfluorescein) or HEX (Hexachloro-Fluorescein) fluorescent dye at the $5^{\prime}$-end.

The polymerase chain reaction (PCR) was performed in a $20-\mu \mathrm{L}$ volume containing 30 to $50 \mathrm{ng}$ of template DNA, $1 \times$ PCR buffer $\left(\mathrm{Mg}^{2+}\right.$ plus) (TaKaRa, Beijing, China), $0.25 \mathrm{~mm}$ deoxynucleoside triphosphates, $0.5 \mu \mathrm{M}$ of each primer set, and $1 \mathrm{U}$ of Taq DNA polymerase (TaKaRa). The PCR amplification was conducted under the following thermal conditions: 4 min at $94{ }^{\circ} \mathrm{C}$ for initial denaturation, followed by 35 cycles of denaturation at $94{ }^{\circ} \mathrm{C}$ for $30 \mathrm{~s}$, annealing at the optimum annealing temperature for $30 \mathrm{~s}$, then at $72^{\circ} \mathrm{C}$ for $45 \mathrm{~s}$, with a final extension at $72{ }^{\circ} \mathrm{C}$ for $10 \mathrm{~min}$. The final reaction was held at $4{ }^{\circ} \mathrm{C}$.

SSR DATA ACQUISITION. The PCR-amplified products were separated using capillary electrophoresis on an ABA-3730XL DNA Analyzer (Thermo Fisher Scientific, Waltham, MA). An internal size standard (GeneScan-500ROX, Thermo Fisher Scientific) was used to estimate the approximate molecular weights of the amplified products. Ultimately, the peaks were shown by size and height using generic description software (GeneMapper version 3.2, Thermo Fisher Scientific).

SSR DATA ANALYSIS. To assess the genetic diversity among the accessions, the following parameters were applied using the statistical software POPGEN version 1.32 (Krawczak et al., 2006): the number of alleles $\left(\mathrm{N}_{\mathrm{a}}\right)$, number of effective alleles $\left(\mathrm{N}_{\mathrm{e}}\right)$, observed heterozygosity $\left(\mathrm{H}_{\mathrm{o}}\right)$, expected heterozygosity $\left(\mathrm{H}_{\mathrm{e}}\right)$, and Shannon's information index (I) for each locus. The PIC and GD of each primer pair was estimated using PowerMarker version 3.25 (Kejun and Muse, 2005). The genetic diversity index among different populations was calculated using GenALEx version 6.41 (standard model) (Peakall and Smouse, 2006).

Genetic distances were calculated in accordance with Nei (1973) and were used to construct a dendrogram based on the unweighted pair-group method of mathematical averages (UPGMA) using MEGA5 software (Tamura et al., 2011), and the dendrogram was visualized using EvolView version 2 (He et al., 2016). A principal coordinate analysis (PCA) and an AMOVA were also conducted with GenALEx version 6.41. The population structure was investigated with STRUCTURE software (Li et al., 2019), which is based on an admixture model with correlated allelic frequencies. The number of populations (K) was set from 2 to 10 , and 10 independent runs for each $\mathrm{K}$ were conducted using a burn-in period of 10,000 steps, followed by 100,000 iterations. The best $\mathrm{K}$ was estimated based on the delta $\mathrm{K}$ method using STRUCTURE HARVESTER (Earl and Vonholdt, 2012).

\section{Results}

Allelic Variance And genetic Diversity. During this study, nine SSR primers were used to detect the molecular variance among the 100 grape samples; 100 unique genotypes were detected (Supplemental Table 1). Each of the nine loci analyzed was polymorphic, and resulted in 186 alleles, with an average of 20.667 alleles per locus (Table 2). $\mathrm{N}_{\mathrm{a}}$ varied from 16 (VVMD7) to 29 (VVMD28). $\mathrm{N}_{\mathrm{e}}$ ranged from 8.306 to 17.549 , with a mean value of 11.472 . GD was between 0.883 and 0.943 , with an average of 0.910 . The average value for I was 1.245 , with a range from 0.966 to 1.582 . PIC values varied from 0.873 for VVMD5 to 0.940 for VVMD28, with an average of 0.903 
Table 1. Geographic characteristics and the group information of 100 Vitis materials examined in this study.

\begin{tabular}{|c|c|c|c|c|}
\hline Species & Code no. & Clone & Origin & Cluster no. \\
\hline V. riparia & 83 & DVIT1884 b43-15M44 & United States & I \\
\hline$V$. aestivalis & 84 & DVIT2382Xiaputao & United States & I \\
\hline V. monticola & 85 & DVIT1847Tianshanputao & United States & I \\
\hline$V$. girdiana & 86 & DVIT1387Shanguputao & United States & I \\
\hline \multirow[t]{7}{*}{$V$. davidii } & 88 & ZLL & Hunan Province, $\mathrm{R} 6^{\mathrm{y}}$ & II \\
\hline & 90 & HHBG & Huaihua, Hunan Province, R6 & II \\
\hline & 91 & WH-ci & Wuhan Province, $\mathrm{R}^{\mathrm{y}}$ & II \\
\hline & 98 & Gaoshan-1 & Jiangxi Province, $\mathrm{R} 2^{\mathrm{y}}$ & II \\
\hline & 99 & Ziqiu & Hunan Province, $\mathrm{R} 2^{\mathrm{y}}$ & II \\
\hline & 100 & Gaoshan-2 & Jiangxi Province, $\mathrm{R} 2^{\mathrm{y}}$ & II \\
\hline & 94 & Black pearl & Hunan Province, $\mathrm{R} 6^{\mathrm{y}}$ & II \\
\hline \multirow[t]{4}{*}{ V. amurensis } & 78 & SPT-1 & Northeastern China, R4 ${ }^{y}$ & III \\
\hline & 79 & SPT-2 & Northeastern China, R4 ${ }^{\mathrm{y}}$ & III \\
\hline & 80 & SPT0933 & Northeastern China, R4 $4^{\mathrm{y}}$ & III \\
\hline & 81 & DLS & Beijing Province, R3 $3^{y}$ & III \\
\hline V. amurensis var. yanshanensis & 82 & Beizhi1702 & Beijing Province, $R 3^{y}$ & III \\
\hline \multirow[t]{11}{*}{$V$. vinifera } & 72 & Sauvignon Blanc ${ }^{z}$ & France & III \\
\hline & 74 & Carignan $^{z}$ & Spain & III \\
\hline & 75 & Gamay $^{z}$ & Spain & III \\
\hline & 76 & Syrah $^{z}$ & Iran & III \\
\hline & 67 & Cardinal & United States & III \\
\hline & 62 & Muscat Hamburg & England & III \\
\hline & 63 & Shenyangmeigui & China & III \\
\hline & 71 & Augusta & Romania & III \\
\hline & 68 & Miskat Plevenski & Bulgaria & III \\
\hline & 61 & Pobeda & Uzbekistan & III \\
\hline & 69 & Flaming Muscat & South Africa & III \\
\hline Unknown & 56 & MZL-5 & Songxian, Henan Province, $\mathrm{R}^{\mathrm{y}}$ & III \\
\hline Unknown & 55 & MZL-6 & Songxian, Henan Province, $\mathrm{R}^{\mathrm{y}}$ & III \\
\hline \multirow[t]{2}{*}{$V$. betulifolia } & 58 & BYS & Songxian, Henan Province, $\mathrm{R}^{\mathrm{y}}$ & III \\
\hline & 57 & SX & Songxian, Henan Province, $\mathrm{R}^{\mathrm{y}}$ & III \\
\hline \multirow{13}{*}{$V$. ficifolia } & 45 & QTH-6 & Jiaozuo, Henan Province, R6 ${ }^{\mathrm{y}}$ & IV \\
\hline & 44 & NWH1403 & Xinyang, Henan Province, R6 $6^{y}$ & IV \\
\hline & 41 & QYS-8 & Luoyang, Henan Province, R6 ${ }^{\mathrm{y}}$ & IV \\
\hline & 43 & JLG-4 & Luoyang, Henan Province, R6 ${ }^{y}$ & IV \\
\hline & 42 & JLG-1 & Luoyang, Henan Province, $\mathrm{R} 6^{\mathrm{y}}$ & IV \\
\hline & 51 & BTM-1 & Nanyang, Henan Province, $R 6^{y}$ & IV \\
\hline & 53 & FJG-3 & Luoyang, Henan Province, $\mathrm{R} 6^{\mathrm{y}}$ & IV \\
\hline & 52 & $X Y$ & Xinyang, Henan Province, R6 $6^{\mathrm{y}}$ & IV \\
\hline & 47 & QL-3 & Shaanxi Province, $\mathrm{R}^{\mathrm{y}}$ & IV \\
\hline & 46 & HX & Xian, Shaanxi Province, R5 $5^{y}$ & IV \\
\hline & 48 & WDS-1 & Henan Province, $\mathrm{R}^{\mathrm{y}}$ & IV \\
\hline & 50 & SBY-5 & Linzhou, Henan Province, R6 ${ }^{y}$ & IV \\
\hline & 49 & JLG1401 & Luoyang, Henan Province, R6 ${ }^{y}$ & IV \\
\hline
\end{tabular}


Table 1. Continued.

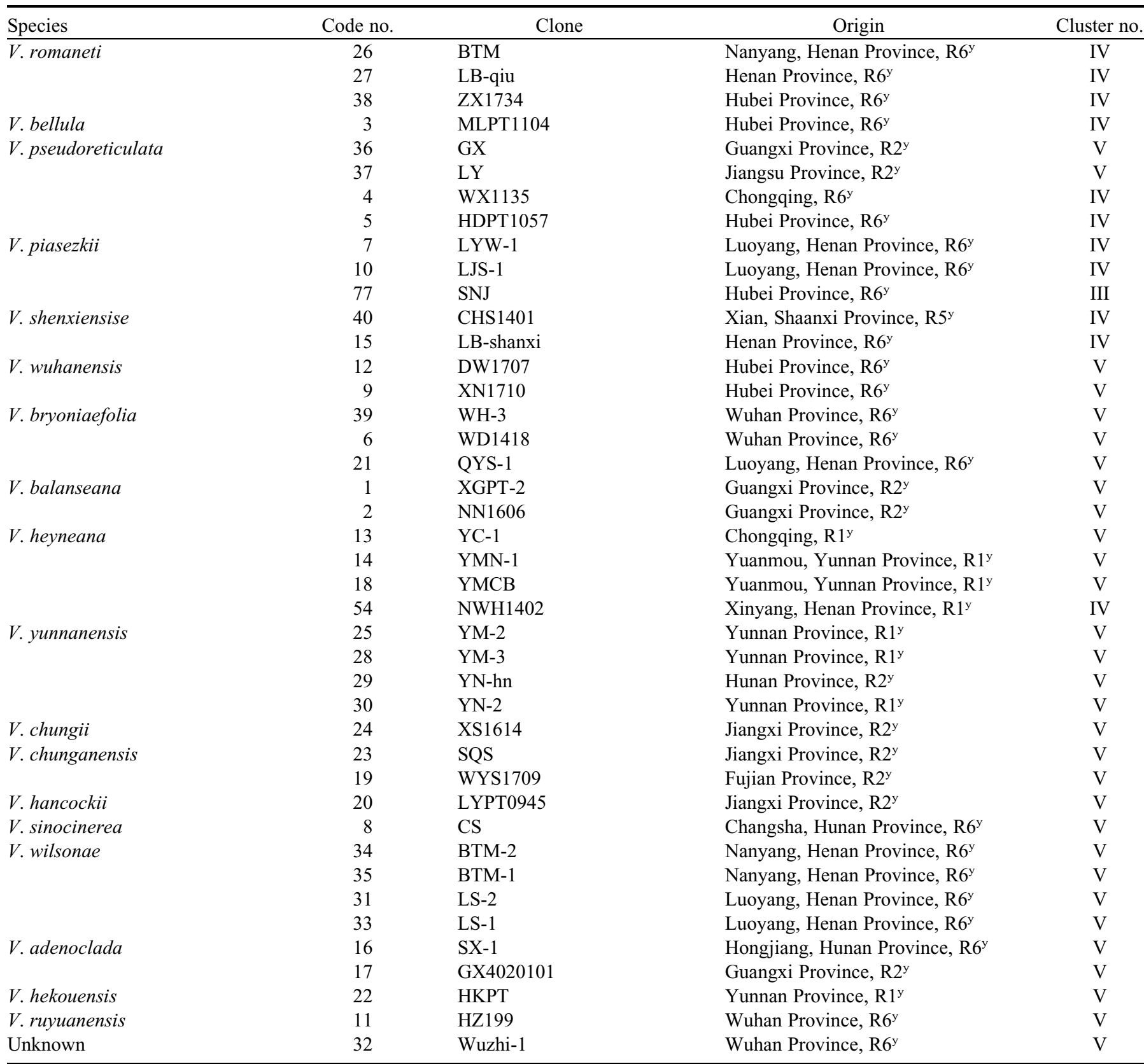

${ }^{\mathrm{z}}$ Sauvignon Blanc, Carignan, Gamay, and Syrah are used for simple sequence repeat standardization for comparison with international databases. ${ }^{\mathrm{y}} \mathrm{R} 1$ = southwestern China (i.e., Yunnan and Chongqing); R2 = southeastern China (i.e., Guangxi, Guangdong, Jiangxi, Jiangsu, and Fujian); R3 = north China (i.e., Beijing); R4 = northeastern China (i.e., Heilongjiang); R5 = northwestern China (i.e., Shanxi and Qinling); R6 = central China (i.e., Hubei, Hunan, Henan).

(Table 2). $\mathrm{H}_{\mathrm{o}}$ ranged from 0.476 to 0.859 , with a mean value of $0.644 ; \mathrm{H}_{\mathrm{e}}$ ranged from 0.503 to 0.726 , with a mean value of 0.608 (Table 2). The fixation index (F) values were close to zero for most of the loci, indicating that the locus fit HardyWeinberg equilibrium. The gene flow values of all the SSR loci were less than one, revealing that the allelic variation at different SSR loci showed genetic differentiation among the different materials.

According to the cluster analysis, 100 grape samples could be divided into five groups. The genetic diversity of the different groups (I, II, III, IV, and V) evaluated using the SSR markers is shown in Table 3. According to the values for $\mathrm{N}_{\mathrm{e}}$ and I, group $\mathrm{V}$ had the highest diversity, followed by groups IV, III, I, and II, whereas the number of accessions in groups III and II are more than group IV and I, respectively, which indicates a little relationship with the number of accessions in each group.

To understand the genetic variation in grape accessions from different origins, genetic diversity was also evaluated with the SSR data (Table 4). Central China (R6) had the highest values 
Table 2. Genetic diversity analysis of the 100 Vitis accessions by the nine simple sequence repeat markers.

\begin{tabular}{|c|c|c|c|c|c|c|c|c|c|}
\hline \multirow[b]{2}{*}{ Locus } & \multicolumn{9}{|c|}{ Parameter $^{z}$} \\
\hline & $\mathrm{N}_{\mathrm{a}}$ & $\mathrm{N}_{\mathrm{e}}$ & $\mathrm{H}_{\mathrm{o}}$ & $\mathrm{H}_{\mathrm{e}}$ & GD & PIC & $\mathrm{I}$ & $\mathrm{F}$ & $\mathrm{Nm}$ \\
\hline VrZAG62 & 20 & 10.959 & 0.637 & 0.646 & 0.909 & 0.902 & 1.319 & -0.023 & 0.608 \\
\hline VrZAG79 & 18 & 11.138 & 0.691 & 0.610 & 0.911 & 0.904 & 1.274 & -0.142 & 0.489 \\
\hline VVMD5 & 19 & 8.306 & 0.582 & 0.544 & 0.883 & 0.873 & 1.102 & -0.091 & 0.413 \\
\hline VVMD7 & 16 & 9.268 & 0.515 & 0.503 & 0.894 & 0.885 & 0.966 & -0.057 & 0.309 \\
\hline VVMD28 & 29 & 17.549 & 0.622 & 0.626 & 0.943 & 0.940 & 1.358 & 0.003 & 0.480 \\
\hline VVMD25 & 21 & 10.455 & 0.751 & 0.667 & 0.906 & 0.899 & 1.358 & -0.171 & 0.675 \\
\hline VVMD27 & 18 & 10.030 & 0.662 & 0.605 & 0.899 & 0.891 & 1.197 & -0.101 & 0.539 \\
\hline Mean & 20.667 & 11.472 & 0.644 & 0.608 & 0.910 & 0.903 & 1.245 & -0.078 & 0.535 \\
\hline
\end{tabular}

${ }^{\mathrm{z}} \mathrm{N}_{\mathrm{a}}=$ observed number of alleles; $\mathrm{N}_{\mathrm{e}}=$ effective number of alleles; $\mathrm{H}_{\mathrm{o}}=$ observed heterozygosity; $\mathrm{H}_{\mathrm{e}}=$ expected heterozygosity; GD = gene diversity; PIC = polymorphism information content; I = Shannon's information index; F = average fixation index; Nm = gene flow estimate according to Wright's equation.

Table 3. The parameters of genetic diversity among five Vitis groups estimated by nine simple sequence repeat markers.

\begin{tabular}{lrccccc}
\hline $\begin{array}{c}\text { Group } \\
\text { no. }\end{array}$ & \multicolumn{5}{c}{ Parameter $^{\mathrm{z}}$} & \begin{tabular}{c} 
Total \\
\cline { 2 - 6 }
\end{tabular} \\
\cline { 2 - 6 } I & $\mathrm{N}_{\mathrm{e}}$ & $\mathrm{I}$ & $\mathrm{H}_{\mathrm{o}}$ & $\mathrm{H}_{\mathrm{e}}$ & genotypes (no.) \\
I & 5.556 & 4.433 & 1.473 & 0.733 & 0.700 & 5 \\
II & 5.667 & 3.455 & 1.345 & 0.744 & 0.650 & 13 \\
III & 11.556 & 5.764 & 2.000 & 0.798 & 0.816 & 28 \\
IV & 12.556 & 7.034 & 2.141 & 0.755 & 0.838 & 24 \\
V & 14.667 & 8.503 & 2.362 & 0.566 & 0.878 & 30
\end{tabular}

${ }^{\mathrm{z}} \mathrm{N}_{\mathrm{a}}=$ observed number of alleles; $\mathrm{N}_{\mathrm{e}}=$ effective number of alleles; $\mathrm{I}=$ Shannon's information index; $\mathrm{H}_{\mathrm{o}}=$ observed heterozygosity; $\mathrm{H}_{\mathrm{e}}=$ expected heterozygosity.

Table 4. The parameters of genetic diversity of Vitis from different regions estimated by nine simple sequence repeat markers.

\begin{tabular}{|c|c|c|c|c|c|c|c|}
\hline \multirow[b]{2}{*}{ Origin $^{z}$} & \multicolumn{6}{|c|}{ Parameter $^{\mathrm{y}}$} & \multirow{2}{*}{$\begin{array}{c}\text { Total } \\
\text { genotypes } \\
\text { (no.) }\end{array}$} \\
\hline & $\mathrm{N}_{\mathrm{a}}$ & $\mathrm{N}_{\mathrm{e}}$ & I & $\mathrm{H}_{\mathrm{o}}$ & $\mathrm{H}_{\mathrm{e}}$ & $\mathrm{F}$ & \\
\hline $\mathrm{R} 1$ & 7.778 & 5.819 & 1.783 & 0.611 & 0.775 & $0.028 * *$ & 8 \\
\hline $\mathrm{R} 2$ & 9.444 & 6.861 & 2.052 & 0.640 & 0.850 & $0.248 * *$ & 13 \\
\hline R3 & 2.667 & 2.415 & 0.866 & 0.722 & 0.528 & -0.378 & 2 \\
\hline $\mathrm{R} 4$ & 3.111 & 2.690 & 0.973 & 0.667 & 0.556 & -0.187 & 3 \\
\hline R5 & 3.667 & 3.003 & 1.126 & 0.778 & 0.611 & $-0.272 * *$ & 3 \\
\hline R6 & 16.778 & 10.002 & 2.469 & 0.692 & 0.891 & $0.225 * * *$ & 48 \\
\hline
\end{tabular}

$\overline{\mathrm{z}} \mathrm{R} 1=$ southwestern China (i.e., Yunnan and Chongqing); R2 $=$ southeastern China (i.e., Guangxi, Guangdong, Jiangxi, Jiangsu, and Fujian); R3 = North China (i.e., Beijing); R4 = northeastern China (i.e., Heilongjiang); R5 = northwestern China (i.e., Shanxi and Qinling); R6 = Central China (i.e., Hubei, Hunan, Henan).

${ }^{\mathrm{y}} \mathrm{N}_{\mathrm{a}}=$ observed number of alleles; $\mathrm{N}_{\mathrm{e}}=$ effective number of alleles; $\mathrm{I}=$ Shannon's information index; $\mathrm{H}_{\mathrm{o}}=$ observed heterozygosity; $\mathrm{H}_{\mathrm{e}}=$ expected heterozygosity; $\mathrm{F}=$ average fixation index.

$* *, * * *$ Significant at $P \leq 0.10$ or 0.05 , respectively, calculated over 1000 permutations.

of the major parameters $\mathrm{N}_{\mathrm{e}}$ and I, followed by southeastern China (R2), southwestern China (R1), northwestern China (R5), northeastern China (R4), and north China (R3), and this trend showed that the genetic diversity of the six regions varied, with the accessions derived from central China exhibiting the greatest genetic diversity. This result may be related to the sample size of each region.
Population differentiation analysis. AMOVA was performed among the 100 accessions by considering the five populations generated by the structure analysis (Table 5). The AMOVA results in Chinese wild grape accessions indicated that $3.28 \%$ of the total variance was among populations, $3.27 \%$ was among individuals within populations, and $93.46 \%$ was within individuals. The inbreeding coefficients within subpopulations relative to the total, within individuals relative to the subpopulation, and within individuals relative to the total parameters were $0.033,0.034$, and 0.065 , respectively (Table 5).

Principal COORdinate analysis. PCA was chosen to complement the cluster analysis information and genetic relationships (Zhu et al., 2018). The PCA results for 100 accessions based on the genetic distance matrix data from the nine SSR markers is shown in Fig. 1. Generally speaking, 100 accessions could be divided into three primary groups (i.e., North American species, European species, and East Asian species), although there was little overlap between the European species and East Asian species, which is consistent with the geography [i.e., North America, East Asia, and Europe (Fig. 1)].

Cluster analysis. To assess the genetic diversity and relationships among 100 Vitis materials, a cluster analysis was conducted based on the genetic distance matrix data estimated by using SSR markers. The dendrogram constructed by UPGMA is shown in Fig. 2. In addition, the North American accessions separated from the other cultivars, forming one individual group — namely, group I — which showed there was a marked divergence between the North American accessions and the Eurasian species of the subgenus Vitis, whereas the cultivated grapes (European species) and Chinese wild grape species (East Asian species) were grouped together in group III. These results provide additional support for the sister relationship between the East Asian species and the European species.

All 100 grape accessions examined were divided into five groups based on the cluster analysis. Group I contained exclusively North American accessions; group II contained only $V$. davidii. Group III was subdivided into three subgroups. Group III-1 contained $V$. amurensis and $V$. amurensis var. yanshanensis, and one accession belonged to $V$. piasezkii. Group III-2 contained European cultivars. Group III-3 included $V$. betulifolia, and two accessions shared similar morphologies with $V$. betulifolia. Group IV consisted of two subgroups. Group IV-1 included $V$. ficifolia. Group IV-2 contained $V$. heyneana, $V$. 
Table 5. Results of the analysis of molecular variance carried out among 100 Vitis accessions considering the five populations generated by the structure analysis.

\begin{tabular}{|c|c|c|c|c|c|c|c|}
\hline \multirow[b]{2}{*}{ Source of variation } & \multirow[b]{2}{*}{ df } & \multirow[b]{2}{*}{ Sum of squares } & \multirow{2}{*}{$\begin{array}{c}\text { Variance } \\
\text { components }\end{array}$} & \multirow{2}{*}{$\begin{array}{l}\text { Proportion of } \\
\text { variation }(\%)\end{array}$} & \multicolumn{3}{|c|}{ Coefficient $^{\mathrm{z}}$} \\
\hline & & & & & $\mathrm{F}_{\text {st }}$ & $\mathrm{F}_{\text {is }}$ & $\mathrm{F}_{\mathrm{it}}$ \\
\hline Among populations & 4 & 36.102 & 0.135 & 3.28 & & & \\
\hline Among individuals within populations & 95 & 390.298 & 0.134 & 3.27 & & & \\
\hline Total & 199 & 810.400 & 4.109 & 100 & 0.033 & 0.034 & 0.065 \\
\hline
\end{tabular}

${ }^{\mathrm{z}} \mathrm{F}_{\mathrm{st}}=$ the inbreeding coefficient within subpopulations relative to the total; $\mathrm{F}_{\mathrm{is}}=$ the inbreeding coefficient within individuals relative to the subpopulation; $F_{i t}=$ the inbreeding coefficient within individuals relative to the total.

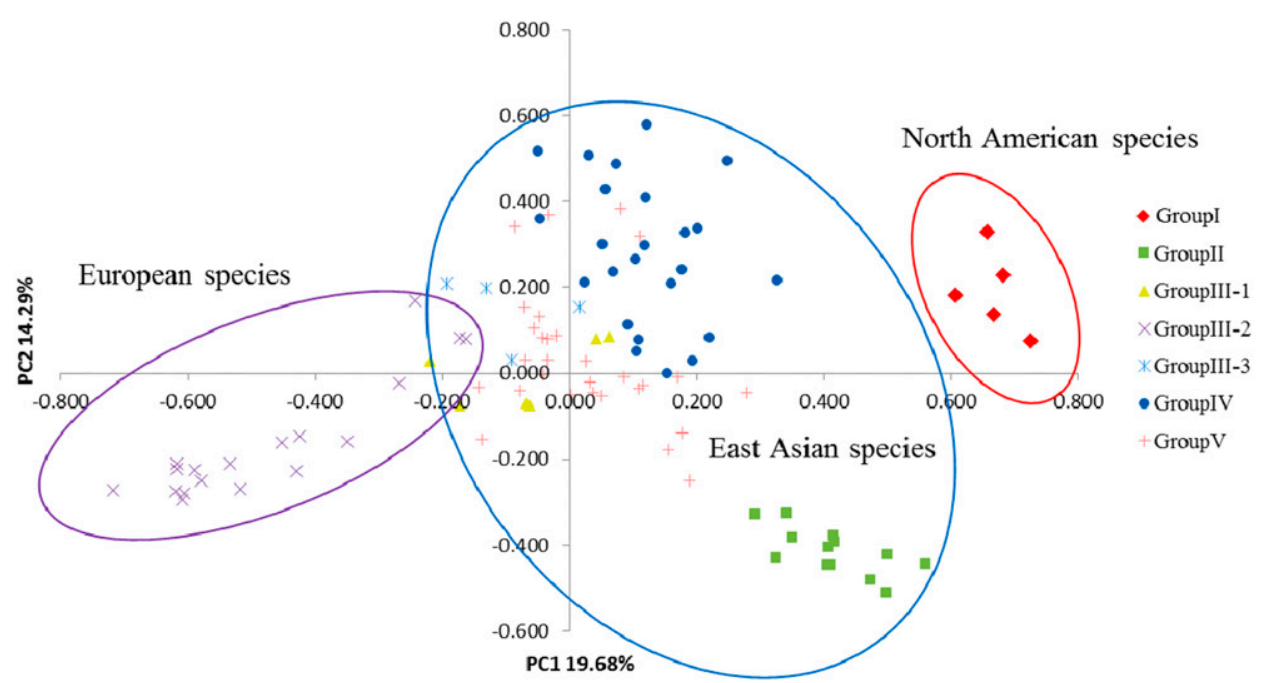

Fig. 1. Associations among the 100 Vitis accessions revealed by principal coordinate (PC) analysis as performed on Nei's genetic distance matrix data calculated from nine simple sequence repeat markers. The red circle represents the North American species. The green circle represents the East Asian species. The purple circle represents the European species.

shenxiensise, $V$. piasezkii, and $V$. romaneti. Group V was the largest, with 30 accessions, and included 15 wild species native to China. Group V was subdivided into 12 subgroups. Group V1 included the single species $V$. wuhanensis. Group V-2 included $V$. bryoniaefolia. Group V-3 contained $V$. balanseana, $V$. pseudoreticulata, and $V$. bellula. Group V-4 included a single species, $V$. yunnanensis. Group V-5 contained $V$. chungii. Group V-6 consisted of $V$. chunganensis. Group V-7 contained a single species, $V$. hancockii. Group V-8 contained only $V$. sinocinerea. Group V-9 included two accessions of $V$. pseudoreticulata, and four accessions of $V$. pseudoreticulata did not group closely within one branch. Group V-10 contained $V$. wilsonae and one accession, Wuzhi-1. Group V-11 consisted of $V$. adenoclada and $V$. hekouensis. Group V-12 contained only $V$. ruyuanensis.

In addition, some important exceptions were discovered by cluster analysis. Three previously undescribed accessions [Wuzhi-1 (ID 32), MZL-5 (ID 56), and MZL-6 (ID 55)] were assigned to the $V$. wilsonae and $V$. betulifolia cluster, with mean genetic distance values of $0.39,0.31$, and 0.38 , respectively.

Population structure analysis. The statistic $\rho \mathrm{K}$ calculated with STRUCTURE was used to determine a suitable K value (population number). The maximum likelihood value and a sharp peak were revealed at $\mathrm{K}=5$. Thus, the 100 grape accessions were divided into five populations: POP I, POP II,
POP III, POP IV, and POP V (Fig. 3 ). On the whole, the results of the genetic structure analysis were consistent with those revealed by the cluster analysis. POP I contained five accessions that originated only from group I, and the accessions of POP I were from the US. POP II included 13 accessions, all of which were from group II, and the accessions of this population were from Hunan, Hubei, Jiangxi, and Wuhan. The 24 accessions that originated from group III were assigned to POP III, which were mostly from Europe and Heilongjiang, among others. POP IV consisted of 18 accessions, which were mostly from Henan, including 14 accessions from group IV, and the other four accessions that originated from group III. POP $\mathrm{V}$ included 40 accessions containing all 30 accessions from POP V along with 10 accessions from group IV, which were from Yunnan, Hunan, Jiangxi, Guangxi, and Fujian, among others.

\section{Discussion}

SSR MARKER. The SSR marker is a powerful, reliable, and useful tool for molecular breeding and for assessing the genetic diversity of plants because of its codominance and ability to reveal a high number of alleles per locus (Bassil et al., 2018; ElEsawi et al., 2016; Liang et al., 2015; Liu et al., 2015; Rodolfi et al., 2018). This is the first study to assess the genetic diversity and relationships among 23 wild Chinese Vitis species/cultivars using this powerful microsatellite technique. The nine SSR markers selected in this study, which are high in polymorphisms, have been used by the European GrapeGen06 consortium (Maul et al., 2012) and have been used frequently to identify grape cultivars (Li et al., 2018; Mihaljevic et al., 2013; This et al., 2004). Internationally, France, Germany, Italy, and other countries have used the nine SSR markers to establish a molecular database of grape cultivars (Maul and Töpfer, 2015), providing an inquiry service for grape research workers. Furthermore, Li et al. $(2017,2018)$ showed that the nine SSR markers can be used to identify the Chinese grape landraces and Euro-American hybrids. 


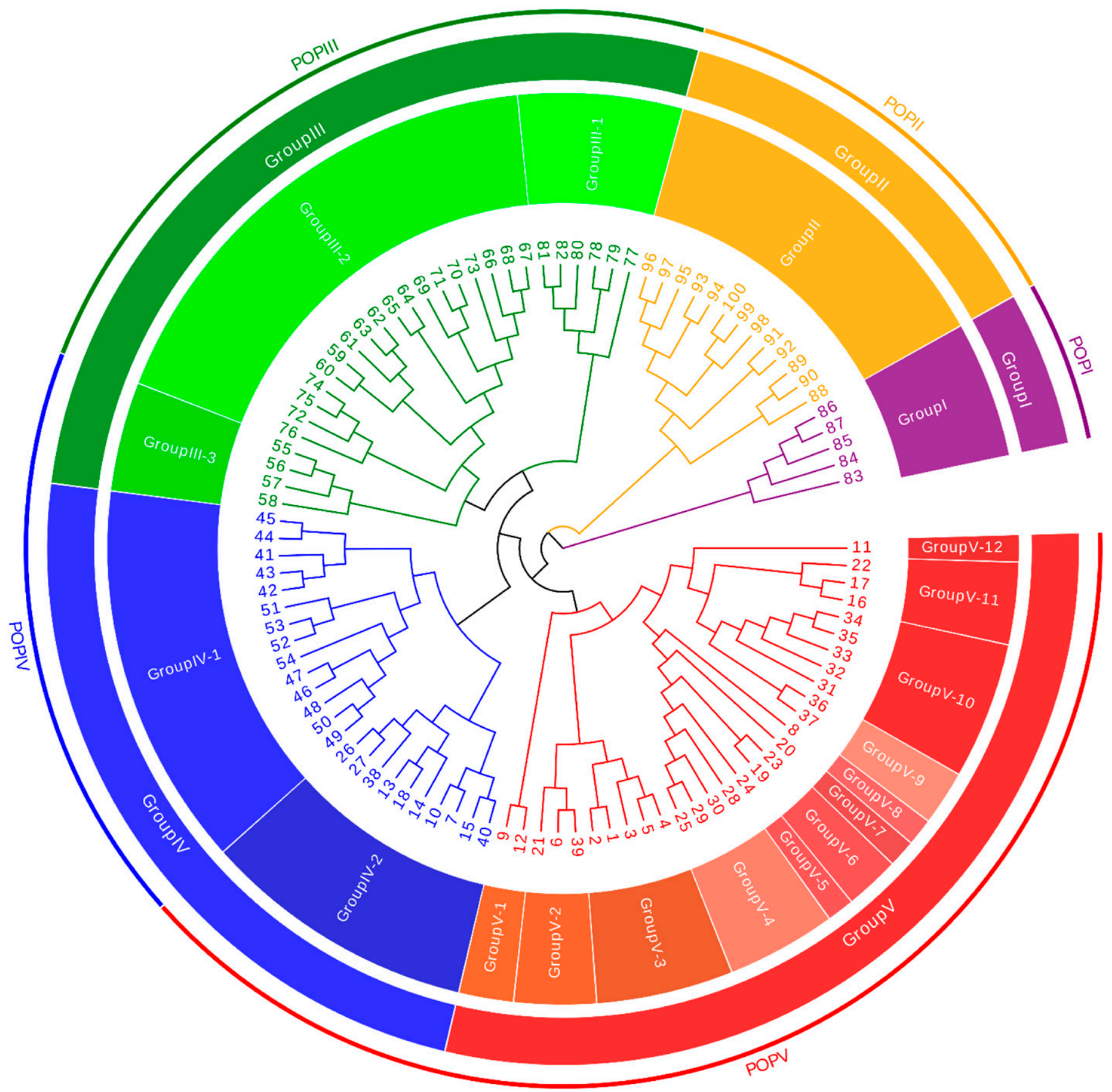

Fig. 2. Phylogenetic trees of 100 Vitis accessions based on simple sequence repeat data. A distance tree was constructed in MEGA5 (Tamura et al., 2011 ) using the unweighted pair-group method of mathematical averages method. Code number is the same reported in Table 1 . POP $=$ population.

The average allele per marker (20.667) is greater than that noted in the earlier report by Jing et al. (2013), who found an average of 10.5 alleles per marker in 62 Chinese wild grapes using 10 SSR markers. The PIC value (0.903) is greater than the values reported by Karataş et al. (2014) (SSR, 0.63) and Ramezani et al. (2009) (SSR, 0.89) in grapes. In particular, the PIC value in our study (0.903) is greater than the earlier report by $\mathrm{Li}$ et al. (2018), who found an average PIC value of 0.815 in 94 cultivated accessions using the nine SSR markers. The greater PIC values evidence a greater genetic diversity in the currently studied Chinese wild grape species than in the cultivated accessions that were studied before. In addition, we found greater $\mathrm{H}_{\mathrm{o}}$ values than expected $(0.644$ and 0.608 , respectively), which is in accordance with Riaz et al. (2018), who reported greater $\mathrm{H}_{\mathrm{o}}$ values than expected among 1378 grape accessions ( 0.742 and 0.678 , respectively). The high heterozygosity values found our study suggest high levels of genetic variation among the analyzed Chinese wild grape species. Currently, many wild grapes have been used in breeding programs, and some even were applied in production directly (Liu et al., 2014). Therefore, this set of SSR primers can be used for the identification of wild grape cultivars in the grape industry. 


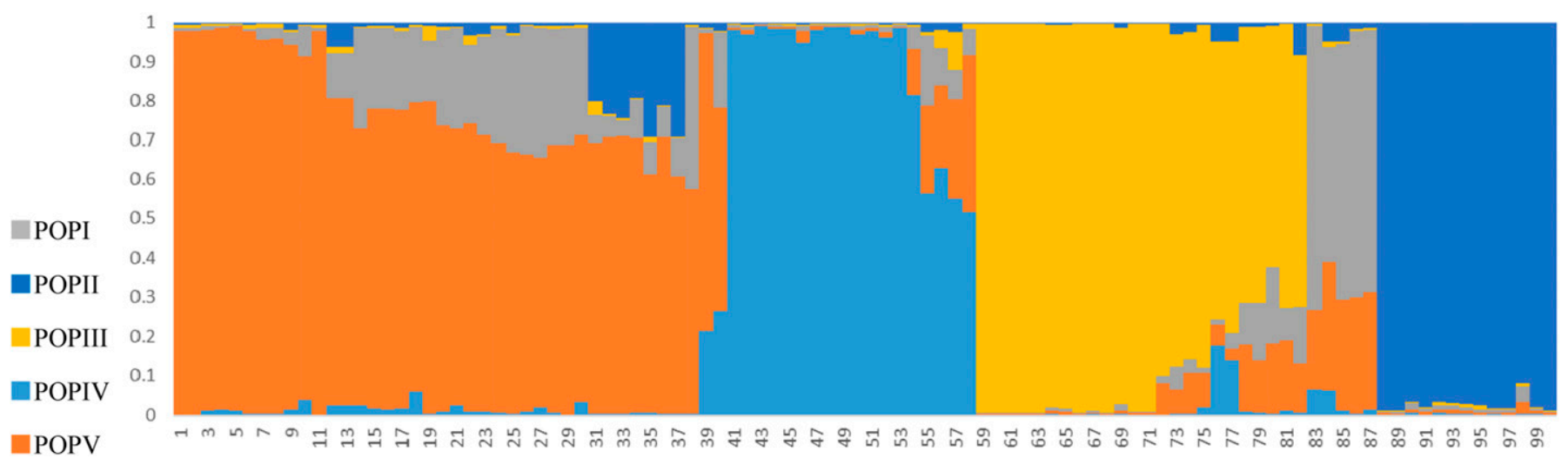

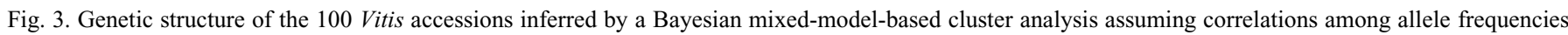
across clusters. Each individual is represented by a thin line partitioned into K colored segments representing the membership fraction in $\mathrm{K}$ clusters. Each color represents a population. $\mathrm{POP}=$ population; $\mathrm{K}=$ number of populations.

SSR markers are also a powerful tool for characterizing the cultivars. In this study, cluster, principal coordinate, and structure analyses allowed us to identify three previously undescribed accessions (Wuzhi-1, MZL-5, and MZL-6). For instance, Wuzhi-1, MZL-5, and MZL-6 not only have a closer relationship with $V$. betulifolia at the molecular level, but also have similar morphological characteristics. The branchlets have arachnoid tomentum and fall off later; the shape of the mature leaf is oval and the number of mature leaf lobes is three; the lower side prostrate hairs between the veins of young leaves are sparse; and there are no glandular hairs on shoots. Bassil et al. (2018) also used SSRs to identify four accessions of previously undescribed hybrid origin during an analysis of the genetic diversity of wild Vaccinium species. Cao et al. (2020) reported that five previously unknown grape accessions were matched by SSRs.

PatTern of Genetic diversity distribution aMong DIFFERENT POPULATIONS. The genetic diversity within and among the different geographic groups in Chinese wild grape species, as demonstrated by $\mathrm{I}$ and $\mathrm{N}_{\mathrm{e}}$, indicates there is significant diversity (Table 4). The Vitis accessions from R6 (i.e., Hubei, Hunan, and Henan) had the highest number of effective alleles, and the I value suggests this region may be the center of diversity for wild grape species. These results may be a result of the large sample size for this region. The $\mathrm{H}_{\mathrm{o}}$ value of the accessions from R1, R2, and R6 was slightly less than the $\mathrm{H}_{\mathrm{e}}$ values, with a contrasting trend for the accessions from R3, R4, and R5. These differences are consistent with the positive $\mathrm{F}$ values, particularly in the populations from R2 and R6, which indicates a close genetic relationship among individuals from the same populations (Table 4). The negative $F$ values for accessions from R2, R3, and R6 indicate an excess of heterozygotes, but only the last one (R6), was statistically significant $(-0.272)$ (Table 4).

The AMOVA results showed that similar levels of genetic variation among and within populations were observed, and low levels of genetic diversity were present among populations, whereas high levels of genetic diversity were found within individuals (Table 5). These results are in accordance with the findings from Riaz et al. (2018), who analyzed the genetic diversity of cultivated and wild grapevine accessions around the Mediterranean Basin and Central Asia. Riaz et al. (2018) also reported that the level of genetic diversity within individuals was greater than that among populations.
Genetic STRUCTURE AND DIFFERENTIATION. A significant differentiation between wild North American Vitis species and Eurasian Vitis species was detected by cluster analysis and PCA (Figs. 1 and 2). This result is consistent with previous studies that support the division of the subgenus Vitis into two clades that mirror their geographic distribution-North America and Eurasia-based on resequencing technology, plastid and nuclear markers, and son on (Klein et al., 2018; Liu et al., 2016; Ma et al., 2018; Péros et al., 2011; Wan et al., 2013). Nevertheless, the relationship between European and East Asian species remains controversial.

In our study, the European species and the cultivated accessions native to China were grouped with two Chinese wild grape species, indicating these Chinese wild grape species are more genetically close to European grapes than North American species. On the other hand, these results were not consistent with the findings of Liang et al. (2019), who indicated that wild East Asian and wild North American accessions shared more similarity in genetic background than Eurasian accessions based on the whole-genome resequencing method. This finding is consistent with those of Liu et al. (2016) and Zhang et al. (2018), all of whom affirmed that the European species (V. vinifera) was grouped within the East Asian clade. Many explanations have been made regarding this phenomenon. For example, Péros et al. (2011) held the opinion that there might be an Asian origin for the subgenus Vitis, and their study suggested that the subgenus Vitis first diverged in Asia and later colonized Europe. Moreover, one hypothesis was suggested that hybridization could be conducive to the integration of the European grape genome into the Chinese germplasm (Zhang et al., 2018). This finding is based on the observation that viticulture has been common since ancient times in regions where wild species grew as well. This finding will increase the gene flow possibility between the cultivated grapes $(V$. vinifera) and the wild grape species.

Furthermore, 100 Vitis accessions were divided into five major groups by their SSRs (Fig. 2), and the PCA also showed similar groupings. The reason that group $\mathrm{V}$ exhibited greater genetic diversity might be related to the sample size. In addition, the American Vitis species from the US grouped together and formed group I. Group II was distributed primarily in the south-central and southeastern regions of China. Groups III and IV were distributed primarily throughout the central region, with some extending to the northern, northeastern, and 
northwestern regions of China, whereas the accessions that originated from Europe grouped together and were also assigned to group III. Group V was distributed primarily throughout the southwestern and southeastern regions of China. Thus, the clustering patterns of most accessions correlated with geographic distribution (Fig. 2).

In addition, a population structure analysis showed that five populations were obtained from the 100 Vitis accessions. However, there were a few discrepancies between the cluster analysis and the structure analysis, which might be because each accession was assigned a fixed branch by cluster analysis, whereas the structural analysis assigned individuals to groups based on the percentage of population members (Zhu et al., 2018). The admixture of all the populations might indicate gene flow in these accessions (Aradhya et al., 2013).

In addition, the results of the cluster analysis revealed a close relationship among $V$. piasezkii, $V$. romaneti, $V$. shenxiensise, and $V$. heyneana. This finding is similar to the results of Ma et al. (2018). Our result supports the idea that some types of $V$. piasezkii have similar morphological characteristics relative to $V$. shenxiensis (Ren and Wen, 2007), which also indicates that a high level of genetic diversity is present within $V$. piasezkii. In addition, according to the review by Wan et al. (2008), $V$. romaneti and $V$. shenxiensise belong to section Romanetianae. $V$. heyneana did not cluster with $V$. ficifolia, unlike the results reported by Zhang et al. (2018) and Wang et al. (2008), but consistent with those of Liu et al. (2016). In addition, the results also revealed a closer relationship between $V$. wilsonae and two accessions of $V$. pseudoreticulata, and this finding is similar to the results of the phylogenetic studies on the grape genus using five plastid and two nuclear markers (Liu et al., 2016). We also found that some accessions belonging to the same species are in different clades (Fig. 2), such as $V$. pseudoreticulata and $V$. piasezkii. This result implies high genetic variation and genetic diversity within species, which was further supported by AMOVA.

\section{Conclusion}

Today, China holds more than 3000 accessions of Vitis, of which some are wild types. These accessions are either native to China or through foreign introduction. With the increase of grape germplasms, genetic information among accessions is becoming more critical for maintenance and utilization strategies in China's breeding programs. We conclude that the estimation of genetic diversity and the population structure of 100 accessions of Vitis using SSR markers may provide more accurate information to grape breeders than the classical pedigree method. In addition, the nine SSR markers used in our study are significantly polymorphic and can be used efficiently to distinguish wild Chinese grape species. Moreover, three previously undescribed accessions were identified to species (Wuzhi-1, MZL-5, and MZL-6). The nine SSR primer pairs in our study may also be of potential value for further research on genetic mapping, marker-assisted selections, and so on, in grapes.

\section{Literature Cited}

Ali, A., Y.B. Pan, Q.N. Wang, J.D. Wang, J.L. Chen, and S.J. Gao. 2019. Genetic diversity and population structure analysis of Saccharum and Erianthus genera using microsatellite (SSR) markers. Sci. Rep. 9:395, doi: 10.1038/s41598-018-36630-7.

Abbasov, M., Z. Akparov, T. Gross, S. Babayeva, V. Izzatullayeva, E. Hajiyev, K. Rustamov, P. Cross, M. Tekin, T. Akar, S.M. Chao, and
R. Brueggeman. 2018. Genetic relationship of diploid wheat (Triticum sp.) species assessed by SSR markers. Genet. Resources Crop Evol. 65:1441-1453, doi: 10.1007/s10722-018-0629-2.

Aradhya, M., Y. Wang, M.A. Walker, B.H. Prins, A.M. Koehmstedt, D. Velasco, and J.E. Preece. 2013. Genetic diversity, structure, and patterns of differentiation in the genus Vitis. Plant Syst. Evol. 299:317-330, doi: 10.1007/s00606-012-0723-4.

Bassil, N., A. Bidani, K. Hummer, L.J. Rowland, J. Olmstead, P. Lyrene, and C. Richards. 2018. Assessing genetic diversity of wild southeastern North American Vaccinium species using microsatellite markers. Genet. Resources Crop Evol. 65:939-950, doi: 10.1007/ s10722-017-0585-2.

Bowers, J., J.M. Boursiquot, P. This, K. Chu, H. Johansson, and C. Meredith. 1999. Historical genetics: The parentage of chardonnay, gamay, and other wine grapes of northeastern France. Science 285:1562-1565, doi: 10.1126/science.285.5433.1562.

Bowers, J.E., G.S. Dangl, R. Vignani, and C.P. Meredith. 1996. Isolation and characterization of new polymorphic simple sequence repeat loci in grape (Vitis vinifera L.). Genome 39:628-633, doi: $10.1139 / \mathrm{g} 96-080$.

Cao, S., S. Stringer, G. Gunawan, C. McGregor, and P.J. Conner. 2020. Genetic diversity and pedigree analysis of muscadine grape using SSR markers. J. Amer. Soc. Hort. Sci. 145:143-151, doi: 10.21273/ JASHS04856-20.

Chao, W.J. and S.Z. Niu. 1981. Preliminary study on isoenzyme of Chinese wild Vitis in China. China Fruits 4:41-44, doi: 10.16626/ j.cnki.issn1000-8047.1981.04.022. (in Chinese).

Earl, D.A. and B.M. Vonholdt. 2012. Structure Harvester: A website and program for visualizing structure output and implementing the evanno method. Conserv. Genet. Resources 4:359-361, doi: 10.1007/s12686-011-9548-7.

El-Esawi, M.A., K. Germaine, P. Bourke, and R. Malone. 2016. Genetic diversity and population structure of Brassica oleracea germplasm in Ireland using SSR markers. C. R. Biol. 339:133-140, doi: 10.1016/j.crvi.2016.02.002.

Fan, X.C., J.F. Jiang, Y. Zhang, H.S. Sun, J. Jiao, and C.H. Liu. 2015. Genetic diversity assessment of Vitis ficifolia Bge. populations from Henan Province of China by SRAP markers. Biotechnol. Biotech. Equipment 29:15-20, doi: 10.1080/13102818.2014.984414.

Guan, C., P. Zhang, C. Hu, S. Chachar, A. Riaz, R. Wang, and Y. Yang. 2019. Genetic diversity, germplasm identification and population structure of Diospyros kaki Thunb. from different geographic regions in China using SSR markers. Scientia Hort. 251:233-240, doi: 10.1016/j.scienta.2019.02.062.

Guo, D.L., J.Y. Zhang, C.H. Liu, G.H. Zhang, and M. Li. 2010. Genetic relationships of Chinese grape accessions to European and American cultivars assessed by microsatellite markers. Biotechnol. Biotech. Equipment 24:2054-2059, doi: 10.2478/v10133-0100073-8.

He, P.C. and W.J. Chao. 1982. Study on pollen electron microscopy of Chinese wild Vitis. China Fruits 3:43-45, doi: 10.7606/j.10041389.2014.04.013. (in Chinese).

He, Z., H. Zhang, S. Gao, M.J. Lercher, W.H. Chen, and S. Hu. 2016. Evolview v2: An online visualization and management tool for customized and annotated phylogenetic trees. Nucl. Acids Res. 44:W236-W241, doi: 10.1093/nar/gkw370.

Jiang, J.F., S. Kell, X.C. Fan, Y. Zhang, W. Wei, D.M. Kang, N. Maxted, B.F. Lloyd, and C.H. Liu. 2015. The wild relatives of grape in China: Diversity, conservation gaps and impact of climate change. Agr. Ecosyst. Environ. 209:155-163, doi: 10.1016/j.agee.2015.03.021.

Jing, Z.B. and X.P. Wang. 2013. Genetic relationship between Chinese wild Vitis species and American and European cultivars based on ISSR markers. Biochem. Syst. Ecol. 46:120-126, doi: 10.1016/j.bse. 2012.08.004.

Jing, Z.B., X.P. Wang, and J.M. Cheng. 2013. Analysis of genetic diversity among Chinese wild Vitis species revealed with SSR and SRAP markers. Genet. Mol. Res. 12:1962-1973, doi: 10.4238/ 2013.June.13.5. 
Karataş, D.D., H. Karataş, V. Laucou, G. Sarikamiş, L. Riahi, R. Bacilieri, and P. This. 2014. Genetic diversity of wild and cultivated grapevine accessions from southeast Turkey. Hereditas 151:73-80, doi: $10.1111 / \mathrm{hrd} 2.00039$.

Kejun, L. and S.V. Muse. 2005. Powermarker: An integrated analysis environment for genetic marker analysis. Bioinformatics 9:21282129, doi: 10.1093/bioinformatics/bti282.

Klein, L.L., A.J. Miller, C. Ciotir, K. Hyma, S. Uribe-Convers, and J. Londo. 2018. High-throughput sequencing data clarify evolutionary relationships among North American Vitis species and improve identification in USDA Vitis germplasm collections. Amer. J. Bot. 105:215-226, doi: 10.1002/ajb2.1033.

Krawczak, M., S. Nikolaus, H. Von Eberstein, P.J.P. Croucher, N.E. El Mokhtari, and S. Schreiber. 2006. Popgen: Population-based recruitment of patients and controls for the analysis of complex genotypephenotype relationships. Community Genet. 9:55-61, doi: 10.1159/ 000090694.

Li, B.B., J.F. Jiang, X.C. Fan, Y. Zhang, H.S. Sun, G.H. Zhang, and C.H. Liu. 2017. Molecular characterization of Chinese grape landraces (Vitis L.) using microsatellite DNA markers. HortScience 52:533-540, doi: 10.21273/HORTSCI11802-17.

Li, B.B., J.F. Jiang, Y. Zhang, X.C. Fan, H.S. Sun, G.H. Zhang, and C.H. Liu. 2018. DNA fingerprinting and genetic diversity analysis of grape cultivars based on SSR markers. J. Plant Genet. Resources 19:301-313, doi: 10.13430/j.cnki.Jpgr.2018.02.017. (in Chinese).

Li, Y., K. Cao, G.R. Zhu, W.C. Fang, C.W. Chen, X.W. Wang, P. Zhao, J. Guo, T.Y. Ding, L.P. Guan, Q. Zhang, W.W. Guo, Z.J. Fei, and L.R. Wang. 2019. Genomic analyses of an extensive collection of wild and cultivated accessions provide new insights into peach breeding history. Genome Biol. 20:36, doi: 10.1186/s13059-0191648-9.

Liang, W., L. Dondini, P.D. Franceschi, R. Paris, S. Sansavini, and S. Tartarini. 2015. Genetic diversity, population structure and construction of a core collection of apple cultivars from Italian germplasm. Plant Mol. Biol. Rpt. 33:458-473, doi: 10.1186/s13059-019-1648-9.

Liang, Z., S. Duan, J. Sheng, S. Zhu, X. Ni, J. Shao, and R. Mao. 2019. Whole-genome resequencing of 472 Vitis accessions for grapevine diversity and demographic history analyses. Nat. Commun. 10:1190, doi: 10.1038/s41467-019-09135-8.

Liu, C.H., X.C. Fan, J.F. Jiang, D.L. Guo, H.S. Sun, Y. Zhang, and J.G. Feng. 2012. Genetic diversity of Chinese wild grape species by SSR and SRAP markers. Biotechnol. Biotech. Equipment 26:2899-2903, doi: 10.5504/bbeq.2011.0146.

Liu, X.Q., S.M. Ickert-Bond, Z.L. Nie, Z. Zhou, L.Q. Chen, and J. Wen. 2016. Phylogeny of the Ampelocissus-Vitis clade in Vitaceae supports the New World origin of the grape genus. Mol. Phylogenet. Evol. 95:217-228, doi: 10.1016/j.ympev.2015.10.013.

Liu, C.H., J.F. Jiang, X.C. Fan, and Y. Zhang. 2014. The utilization of Chinese wild grape species in production and breeding. J. Plant Genet. Resources 15:720-727, doi: 10.13430/j.cnki.Jpgr.2014. 04.006. (in Chinese).

Liu, Q., Y. Song, L. Liu, M. Zhang, J. Sun, S. Zhang, and J. Wu. 2015. Genetic diversity and population structure of pear (Pyrus spp.) collections revealed by a set of core genome-wide SSR markers. Tree Genet. Genomes 11:1-22, doi: 10.1007/s11295-015-0953-z.

Liu, K.Y., F. Xu, X.H. Shi, X.H. Zhong, G.F. Yang, and J.J. Ni. 2013. Relationship analysis for Vitis davidii with SRAP molecular markers. J. Hunan Agr. Univ. 38:607-611, doi: 10.3724/SP.J.1238.2012. 00607. (in Chinese).

Luo, S.L., P.C. He, X.Q. Zheng, and P. Zhou. 2001. Genetic diversity in wild grapes native to China based on randomly amplified polymorphic DNA (RAPD) analysis. Acta Bot. Sin. 43:158-163, doi: 10.1016/S0168-9452(00)00427-1.

Ma, Z.Y., J. Wen, S.M. Ickert-Bond, Z.L. Nie, L.Q. Chen, and X.Q. Liu. 2018. Phylogenomics, biogeography, and adaptive radiation of grapes. Mol. Phylogenet. Evol. 129:258-267, doi: 10.1016/ j.ympev.2018.08.021.
Maul, E., K.N. Sudharma, S. Kecke, G. Marx, and P. This. 2012. The European Vitis database (www.eu-vitis.de): A technical innovation through an online uploading and interactive modification systemVitis27985, doi: 10.5073/VITIS.2012.51.79-85.

Maul, E. and R. Töpfer. 2015. Vitis International Variety Catalogue (VIVC): A cultivar database referenced by genetic profiles and morphology. Bio. Web Conf. 5:01009, doi: 10.1051/bioconf/20150501009.

Mihaljevic, M.Z., S. Simon, I. Pejic, F. Carka, R. Sevo, A. Kojic, and D. Preiner. 2013. Molecular characterization of old local grapevine varieties from southeast European countries. Vitis 52:69-76, doi: 10.5073/vitis.2013.52.69-76.

Nei, M. 1973. Analysis of gene diversity in subdivided populations. Proc. Nat. Acad. Sci. USA 70:3321-3323, doi: 10.1073/pnas.70.12.3321.

Peakall, R. and P.E. Smouse. 2006. GENALEX 6: Genetic analysis in Excel: Population genetic software for teaching and research. Mol. Ecol. Notes 6:288-295, doi: 10.1111/j.1471-8286.2005.01155.x.

Péros, J.P., G. Berger, A. Portemont, J.M. Boursiquot, and T. Lacombe. 2011. Genetic variation and biogeography of the disjunct Vitis subg. Vitis (Vitaceae). J. Biogeogr. 38:471-486, doi: 10.1111/ j.1365-2699.2010.02410.x.

Queiroz, A., A. Assunção, I. Ramadas, W. Viegas, and M.M. Veloso. 2015. Molecular characterization of Portuguese pear landraces (Pyrus communis L.) using SSR markers. Scientia Hort. 183:7276, doi: 10.1016/j.scienta.2014.11.016.

Ramezani, A., R. Haddad, M. Dorostkar, M. Mardi, and M. Naghavi. 2009. Evaluation of genetic diversity of Iranian grapevine accessions using microsatellite markers. Vitis 48:151-152, doi: 10.1007/ s00122-011-1585-9.

Ren, H. and J. Wen. 2007. VITIS Linnaeus, p. 210-222. In: H. Peng (ed.). Flora of China (English edition). Science Press, Beijing, China. Riaz, S., G. De Lorenzis, D. Velasco, A. Koehmstedt, D. Maghradze, Z. Bobokashvili, and O. Failla. 2018. Genetic diversity analysis of cultivated and wild grapevine (Vitis vinifera L.) accessions around the Mediterranean Basin and Central Asia. BMC Plant Biol. 18:137, doi: 10.1186/s12870-018-1351-0.

Rodolfi, M., A. Silvanini, B. Chiancone, M. Marieschi, A. Fabbri, R. Bruni, and T. Ganino. 2018. Identification and genetic structure of wild Italian Humulus lupulus L. and comparison with European and American hop cultivars using nuclear microsatellite markers. Genet. Resources Crop Evol. 65:1405-1422, doi: 10.1007/s10722-0180622-9.

Sefc, K.M., F. Regner, E. Turetschek, J. Glossl, and H. Steinkellner. 1999. Identification of microsatellite sequences in Vitis riparia and their applicability for genotyping of different Vitis species. Genome 42:367-373, doi: 10.1139/g98-168.

Tamura, K., D. Peterson, N. Peterson, G. Stecher, M. Nei, and S. Kumar. 2011. MEGA5: Molecular evolutionary genetics analysis using maximum likelihood, evolutionary distance, and maximum parsimony methods. Mol. Biol. Evol. 28:2731-2739, doi: 10.1093/ molbev/msr121.

This, P., A. Jung, P. Boccacci, J. Borrego, R. Botta, L. Costantini, M. Crespan, G.S. Dangl, C. Eisenheld, F. Ferreira-Monteiro, J. Grando, S. Ibanez, T. Lacombe, V. Laucou, R. Magalhaes, C.P. Meredith, N. Milani, E. Peterlunger, F. Regner, L. Zulini, and E. Maul. 2004. Development of a standard set of microsatellite reference alleles for identification of grape cultivars. Theor. Appl. Genet. 109:14481458, doi: 10.1007/s00122-004-1760-3.

Thomas, M.R. and N.S. Scott. 1993. Microsatellite repeats in grapevine reveal DNA polymorphisms when analysed as sequence-tagged sites (STSs). Theor. Appl. Genet. 86:985-990, doi: 10.1007/BF00211051.

Wan, Y., H.R. Schwaninger, A.M. Baldo, J.A. Labate, G.Y. Zhong, and C.J. Simon. 2013. A phylogenetic analysis of the grape genus (Vitis L.) reveals broad reticulation and concurrent diversification during neogene and quaternary climate change. BMC Evol. Biol. 13:141, doi: 10.1186/1471-2148-13-141.

Wan, Y., H. Schwaninger, D. Li, C.J. Simon, Y. Wang, and C. Zhang. 2008. A review of taxonomic research in Chinese wild grapes. Vitis 47:81-88, doi: 10.5073/vitis.2008.47.81-88. 
Wang, J., C.H. Liu, X.C. Fan, H.S. Sun, and D. Dong. 2008. Study on the biodiversity of the morphology and polymorphism based on SSR markers for Vitis ficifolia native to Henan Province in China. J. Fruit Sci. 4:496-500, doi: 10.3724/SP.J.1148.2008.00259. (in Chinese).

Zhao, T.T., W.X. Ma, Q.H. Ma, Z. Yang, and L.J. Wang. 2020. Genetic diversity and population structure of Chinese Corylus heterophylla and Corylus kweichowensis using simple sequence repeat markers. J. Amer. Soc. Hort. Sci. 145:1-10, doi: 10.21273/JASHS04887-19.

Zhang, X., P. Gong, Y. Shi, Y. Wang, and C. Zhang. 2018. Genetic inter-relationships among Chinese wild grapes based on SRAP marker analyses. Vitis 57:151-157, doi: 10.5073/vitis.2018.57.
Zhang, Y.H., C.H. Liu, X.C. Fan, Y. Zhang, H.S. Sun, B. Peng, and J.F. Jiang. 2011. Application of ISSR markers in classification of wild grapes in China. J. Fruit Sci. 28:406-412, doi: 10.13925/ j.cnki.gsxb.2011.03.012. (in Chinese).

Zhou, Y., M. Massonnet, J.S. Sanjak, D. Cantu, and B.S. Gaut. 2017. Evolutionary genomics of grape (Vitis vinifera ssp. vinifera) domestication. Proc. Natl. Acad. Sci. USA 114:11715-11720, doi: 10.1073/ pnas. 1709257114.

Zhu, S.Y., X.L. Zhang, Q. Liu, T.K. Luo, and Z. Tang. 2018. The genetic diversity and relationships of cauliflower (Brassica oleracea var. botrytis) inbred lines assessed by using SSR markers. PLoS One 13:e208551, doi: 10.1371/journal.pone.0208551. 
Supplemental Table 1. Genetic profiles of 100 Vitis accessions at nine microsatellite loci.

\begin{tabular}{|c|c|c|c|c|c|c|c|c|c|}
\hline \multirow[b]{2}{*}{ Code no. } & \multicolumn{9}{|c|}{ Microsatellite loci } \\
\hline & VrZAG62 & VrZAG79 & VVS2 & VVMD5 & VVMD7 & VVMD28 & VVMD32 & VVMD25 & VVMD27 \\
\hline 1 & $190 / 196$ & $248 / 250$ & $135 / 139$ & $245 / 245$ & $259 / 263$ & $243 / 249$ & $180 / 246$ & $236 / 238$ & $175 / 179$ \\
\hline 2 & $190 / 196$ & $248 / 250$ & $135 / 139$ & $245 / 245$ & $259 / 263$ & $249 / 249$ & $246 / 246$ & $236 / 238$ & $175 / 179$ \\
\hline 4 & $170 / 198$ & $256 / 264$ & $121 / 131$ & $249 / 255$ & $243 / 251$ & $223 / 235$ & $236 / 238$ & $260 / 260$ & $185 / 197$ \\
\hline 5 & $190 / 194$ & $246 / 260$ & $123 / 133$ & $243 / 245$ & $243 / 251$ & $245 / 261$ & $236 / 238$ & $250 / 252$ & $187 / 209$ \\
\hline 6 & $182 / 182$ & $242 / 252$ & $129 / 129$ & $245 / 245$ & $231 / 247$ & $227 / 243$ & $220 / 220$ & $238 / 238$ & $183 / 201$ \\
\hline 8 & $186 / 188$ & $240 / 240$ & $133 / 133$ & $235 / 235$ & $241 / 243$ & $255 / 255$ & $228 / 228$ & $252 / 268$ & $181 / 191$ \\
\hline 9 & $182 / 182$ & $242 / 254$ & $137 / 153$ & $239 / 241$ & $241 / 247$ & $227 / 227$ & $240 / 246$ & $230 / 242$ & $183 / 187$ \\
\hline 10 & $206 / 206$ & $242 / 254$ & $127 / 127$ & $243 / 245$ & $237 / 241$ & $227 / 249$ & $234 / 244$ & $234 / 250$ & $193 / 193$ \\
\hline 11 & $188 / 190$ & $? / ?$ & $139 / 143$ & $243 / 243$ & $? / ?$ & $? / ?$ & $238 / 238$ & $246 / 252$ & $181 / 189$ \\
\hline 12 & $182 / 192$ & $242 / 242$ & $139 / 145$ & $233 / 235$ & $231 / 231$ & $241 / 251$ & $234 / 258$ & $242 / 242$ & $183 / 187$ \\
\hline 13 & $172 / 172$ & $234 / 250$ & $127 / 155$ & $245 / 245$ & $231 / 239$ & $247 / 255$ & $246 / 246$ & $238 / 272$ & $179 / 181$ \\
\hline 18 & $174 / 174$ & $234 / 250$ & $129 / 155$ & $245 / 245$ & $231 / 237$ & $249 / 257$ & $246 / 246$ & $240 / 274$ & $179 / 181$ \\
\hline 19 & $182 / 186$ & $236 / 248$ & $131 / 135$ & $229 / 251$ & $233 / 233$ & $229 / 229$ & $246 / 248$ & $236 / 256$ & $179 / 199$ \\
\hline 20 & $172 / 186$ & $240 / 240$ & $137 / 147$ & $247 / 247$ & $243 / 243$ & $229 / 239$ & $220 / 220$ & $246 / 248$ & $201 / 201$ \\
\hline 21 & $194 / 194$ & $244 / 250$ & $123 / 129$ & $245 / 245$ & $237 / 237$ & $225 / 241$ & $218 / 218$ & $236 / 236$ & $177 / 183$ \\
\hline 22 & $188 / 188$ & $236 / 236$ & $123 / 123$ & $243 / 245$ & $245 / 245$ & $219 / 219$ & $242 / 246$ & $234 / 246$ & $179 / 179$ \\
\hline 23 & $186 / 186$ & $250 / 258$ & $121 / 133$ & $231 / 233$ & $223 / 233$ & $229 / 229$ & $234 / 234$ & $260 / 262$ & $175 / 179$ \\
\hline 24 & $174 / 200$ & $250 / 256$ & $143 / 149$ & $243 / 243$ & $243 / 243$ & $229 / 229$ & $250 / 250$ & $236 / 236$ & $179 / 207$ \\
\hline 25 & $186 / 186$ & $240 / 248$ & $139 / 139$ & $243 / 243$ & $241 / 243$ & $229 / 245$ & $216 / 250$ & $244 / 252$ & $179 / 181$ \\
\hline 26 & $196 / 206$ & $246 / 254$ & $131 / 135$ & $239 / 243$ & $241 / 243$ & $221 / 243$ & $244 / 244$ & $244 / 258$ & $179 / 179$ \\
\hline 27 & $198 / 200$ & $246 / 248$ & $135 / 139$ & $243 / 243$ & $239 / 243$ & $239 / 259$ & $244 / 246$ & $248 / 254$ & $179 / 181$ \\
\hline 28 & $186 / 186$ & $242 / 242$ & $133 / 133$ & $243 / 243$ & $243 / 243$ & $229 / 245$ & $240 / 246$ & $252 / 252$ & $179 / 179$ \\
\hline 36 & $192 / 192$ & $256 / 258$ & $125 / 139$ & $247 / 251$ & $229 / 229$ & $249 / 251$ & $232 / 232$ & $250 / 260$ & $177 / 177$ \\
\hline 37 & $190 / 190$ & $256 / 258$ & $125 / 139$ & $247 / 251$ & $229 / 229$ & $249 / 251$ & $232 / 232$ & $250 / 260$ & $177 / 177$ \\
\hline 38 & $212 / 212$ & $246 / 246$ & $131 / 137$ & $239 / 243$ & $239 / 241$ & $245 / 245$ & $228 / 244$ & $236 / 254$ & $179 / 189$ \\
\hline 39 & $194 / 194$ & $252 / 256$ & $129 / 135$ & $245 / 245$ & $237 / 237$ & $227 / 243$ & $220 / 220$ & $238 / 238$ & $189 / 199$ \\
\hline 40 & $186 / 192$ & $240 / 256$ & $125 / 129$ & $243 / 243$ & $237 / 237$ & $239 / 243$ & $234 / 236$ & $234 / 258$ & $179 / 187$ \\
\hline 41 & $194 / 194$ & $256 / 266$ & $129 / 163$ & $233 / 235$ & $237 / 237$ & $217 / 245$ & $238 / 240$ & $256 / 256$ & $189 / 193$ \\
\hline 42 & $194 / 194$ & $246 / 256$ & $129 / 139$ & $235 / 235$ & $237 / 245$ & $239 / 241$ & $238 / 238$ & $248 / 254$ & $195 / 195$ \\
\hline 43 & $194 / 194$ & $246 / 256$ & $129 / 129$ & $235 / 241$ & $235 / 237$ & $239 / 239$ & $238 / 238$ & $240 / 246$ & $189 / 195$ \\
\hline 44 & $174 / 174$ & $246 / 252$ & $129 / 159$ & $231 / 235$ & $237 / 237$ & $235 / 239$ & $236 / 238$ & $252 / 256$ & $185 / 189$ \\
\hline 45 & $184 / 194$ & $256 / 256$ & $131 / 131$ & $235 / 241$ & $237 / 237$ & $235 / 239$ & $236 / 238$ & $250 / 250$ & $185 / 189$ \\
\hline 46 & $192 / 192$ & $252 / 258$ & $135 / 167$ & $243 / 245$ & $233 / 237$ & $235 / 239$ & $234 / 240$ & $246 / 250$ & $189 / 189$ \\
\hline 47 & $192 / 192$ & $246 / 258$ & $135 / 165$ & $231 / 243$ & $231 / 237$ & $235 / 239$ & $240 / 240$ & $240 / 246$ & $189 / 193$ \\
\hline 48 & $184 / 192$ & $246 / 252$ & $127 / 167$ & $235 / 243$ & $235 / 235$ & $235 / 245$ & $238 / 238$ & $240 / 246$ & $197 / 197$ \\
\hline 49 & $172 / 192$ & $252 / 256$ & $127 / 155$ & $243 / 243$ & $237 / 237$ & $235 / 239$ & $238 / 238$ & $240 / 260$ & $185 / 189$ \\
\hline 50 & $192 / 192$ & $252 / 282$ & $133 / 151$ & $239 / 243$ & $237 / 237$ & $217 / 235$ & $238 / 238$ & $246 / 262$ & $193 / 197$ \\
\hline 51 & $172 / 184$ & $252 / 256$ & $155 / 165$ & $235 / 259$ & $235 / 237$ & $239 / 247$ & $240 / 240$ & $240 / 248$ & $185 / 193$ \\
\hline 52 & $174 / 194$ & $256 / 258$ & $131 / 163$ & $231 / 243$ & $235 / 237$ & $241 / 243$ & $238 / 242$ & $246 / 252$ & $185 / 185$ \\
\hline 53 & $192 / 192$ & $246 / 258$ & $129 / 139$ & $235 / 243$ & $235 / 235$ & $217 / 217$ & $238 / 240$ & $246 / 252$ & $185 / 185$ \\
\hline 54 & $174 / 190$ & $250 / 264$ & $127 / 135$ & $239 / 243$ & $237 / 243$ & $235 / 235$ & $236 / 238$ & $238 / 262$ & $193 / 193$ \\
\hline 55 & $184 / 192$ & $240 / 254$ & $125 / 131$ & $231 / 245$ & $235 / 237$ & $223 / 245$ & $236 / 244$ & $232 / 246$ & $185 / 187$ \\
\hline 56 & $184 / 204$ & $248 / 254$ & $125 / 135$ & $231 / 243$ & $237 / 241$ & $223 / 243$ & $236 / 244$ & $246 / 248$ & $181 / 181$ \\
\hline 57 & $184 / 210$ & $254 / 258$ & $133 / 135$ & $233 / 251$ & $237 / 237$ & $241 / 249$ & $238 / 244$ & $238 / 246$ & $181 / 187$ \\
\hline
\end{tabular}

Continued next page 
Supplemental Table 1. Continued.

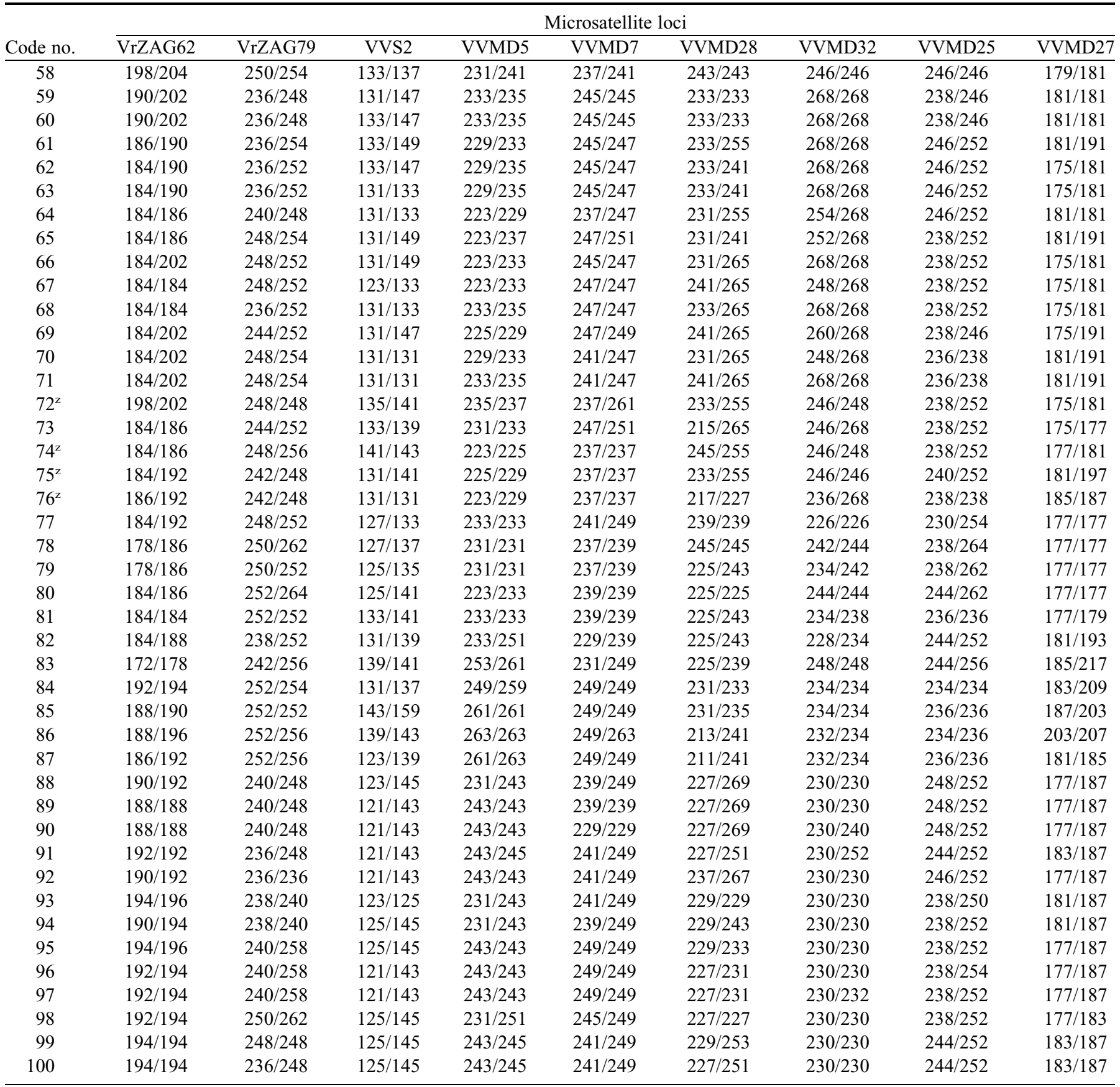

$\overline{\mathrm{z}} 72,74,75$, and 76 are used for simple sequence repeat standardization for comparison with international databases. Code number is the same reported in Table 1. 